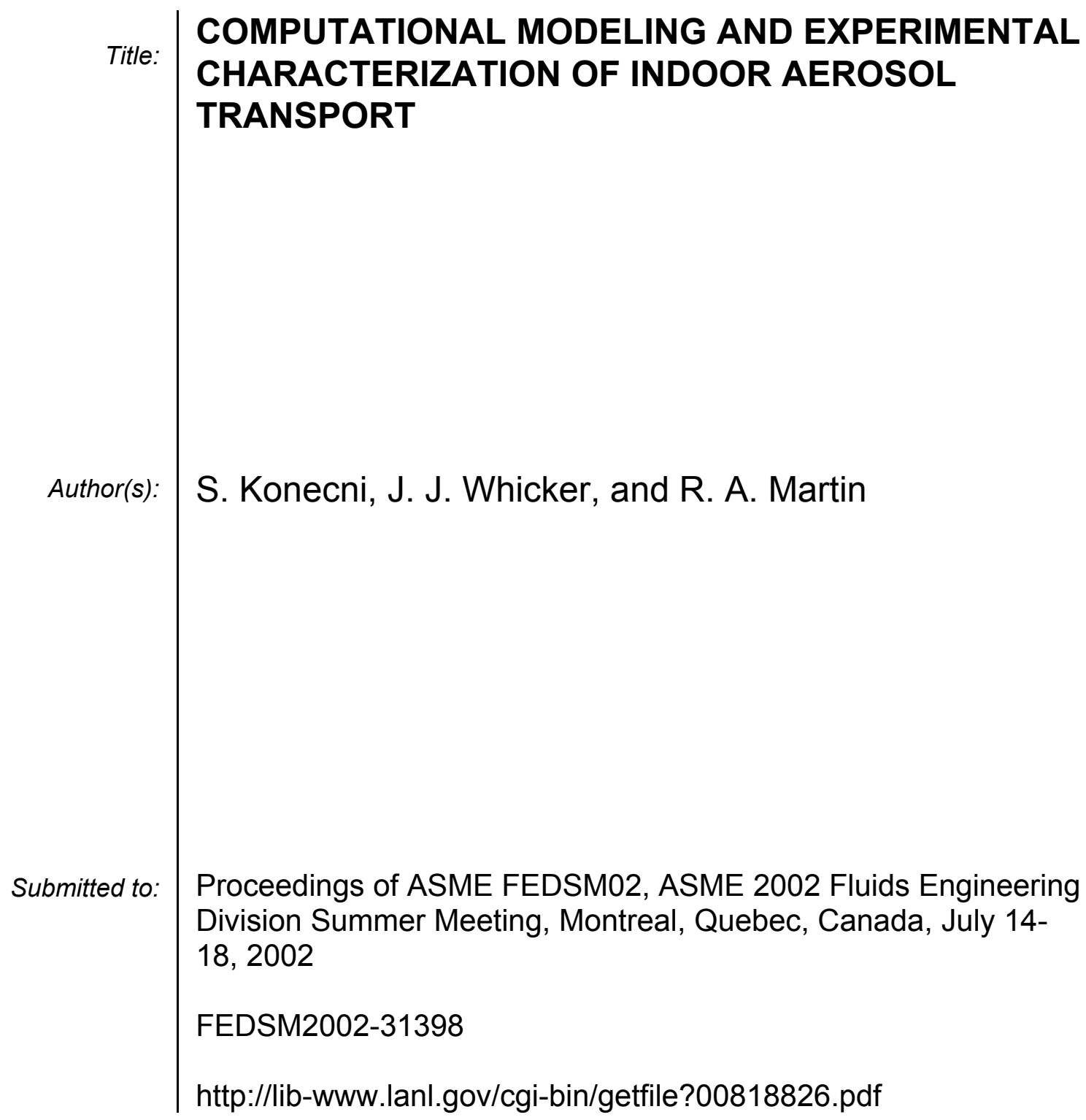


FEDSM2002-31398

\title{
COMPUTATIONAL MODELING AND EXPERIMENTAL CHARACTERIZATION OF INDOOR AEROSOL TRANSPORT
}

\author{
S. Konecni, J. J. Whicker*, and R. A. Martin \\ Engineering Sciences and Applications Division \\ *Health Physics Measurements Group \\ Los Alamos National Laboratory \\ Los Alamos, NM 87545
}

\begin{abstract}
When a hazardous aerosol or gas is inadvertently or deliberately released in an occupied facility, the airborne material presents a hazard to people. Inadvertent accidents and exposures continue to occur in Los Alamos and other nuclear facilities despite state-of-art engineering and administrative controls, and heightened diligence. Despite the obvious need in occupational settings and for homeland defense, the body of research in hazardous aerosol dispersion and control in large, complex, ventilated enclosures is extremely limited. The science governing generation, transport, inhalation, and detection of airborne hazards is lacking and must be developed to where it can be used by engineers or safety professionals in the prediction of worker exposure, in the prevention of accidents, or in the mitigation of terrorist actions.

In this study, a commercial computational fluid dynamics (CFD) code, CFX5.4, and experiments were used to assess flow field characteristics, and to investigate aerosol release and transport in a large, ventilated workroom in a facility at Savannah River Site. Steady state CFD results illustrating a complex, ventilation-induced, flow field with vortices, velocity gradients, and quiet zones are presented, as are timedependent CFD and experimental aerosol dispersion results. The comparison of response times between CFD and experimental results was favorable.

It is believed that future applications of CFD and experiments can have a favorable impact on the design of ventilation (HVAC) systems and worker safety with consideration to facility costs. Ultimately, statistical methods will be used in conjunction with CFD calculations to determine the optimal number and location of detectors, as well as optimal egress routes in event of a release.
\end{abstract}

\section{INTRODUCTION}

For over 20 years, the Engineering Sciences and Applications Division (ESA) and Health Physics Measurements (ESH-4) Group at Los Alamos National
Laboratory (Los Alamos) have been developing new technologies using analytical and experimental tools to aid in the design of nuclear facilities.

These technologies can be used to guide ventilation system design and detector placement decisions for new construction programs, when modifying old facilities, or for evaluation of adequate placement in existing rooms. Also, because research has demonstrated that effective placement of real-time air monitors in large nuclear facilities is critical to radiation safety of workers, we have developed these technologies to aid in decisions regarding placement of aerosol (plutonium) and gas (tritium) detectors. Further, these tools can be used to determine the cause of and help mitigate future nuclear accidents or terrorist actions involving hazardous aerosol or gas dispersion.

Release of radioactive material could occur in Department of Energy (DOE) research and production facilities such as those located at Lawrence Livermore National Laboratory (LLNL), Sandia National Laboratory (SNL), Savannah River Site (SRS), or Los Alamos. Therefore, Federal Regulation 10 CFR 835 (DOE 1999a) requires real-time air monitoring of radioactive materials using Continuous Air Monitors (CAMs) including tritium gas detectors in normally occupied work areas where an individual is likely to receive an exposure of 40 or more Derived Air Concentration-hours (DAC-hours) in a year (which relates to $100 \mathrm{mRem}$ ). Such CAMs or tritium detectors are needed where there is a need to alert individuals to unexpected increases in airborne radioactivity.

For example, CAMs are used to protect workers by monitoring the level of airborne radioactive materials within a room. Once a preset radioactivity level is exceeded, a CAM alarm is triggered alerting the workers to potential hazard and prompting them to evacuate the room. Knowledge of aerosol or gas dispersion patterns in work areas is important to ensuring the CAMs are located in quantities and in positions that provide adequate worker protection. Traditionally, CAMs at Los Alamos plutonium facilities have been located at room exhaust points, but studies have shown that worker protection 
could be improved using a different placement strategy. (Whicker, 1996). In addition, a previous CAM placement study (Konecni, et al., 2000) reported CFD and experimental results obtained in a large, ventilated, laboratory in the main plutonium facility at Los Alamos.

Similar considerations apply to facilities that primarily perform operations with tritium gas, and therefore require the placement of tritium gas detectors.

The main purposes of this study were to use CFD to evaluate a ventilation-system-induced flow field, calculate gas dispersion, benchmark the calculations with experimental measurements, and to provide this data to Savannah River for evaluation of tritium detector placement in a large operational facility.

\section{NUMERICAL METHOD}

CFD codes offer some advantages over experimental techniques in investigating fluid flow. These advantages can include savings in time and cost associated with the alternative, namely, constructing and performing large-scale experiments. In addition, CFD codes allow detailed flow visualization, as well as the ability to conveniently perform parametric sensitivity and optimization studies, and the ability to evaluate room re-configurations. Finally, CFD analysis is the only possible approach to investigate flow fields and aerosol dispersion in a room that is in the design stage.

The flow field and aerosol dispersion in the room studied here was simulated using CFX5.4, a commercially available CFD package. CFD models provide a simultaneous numerical solution of continuity, Navier-Stokes, and energy equations for a flow-field geometry with specified boundary conditions. CFX5.4 uses a finite volume (finite difference) scheme based on the SIMPLEC mathematical algorithm discussed by Van Dormaal and Raithby (1984). A predecessor of this algorithm, SIMPLE is given by Patankar (1980).

\section{ROOM CONFIGURATION AND CFD MODEL}

The SRS room geometry is shown in Fig.1 as isometric view with some features labeled. This room was modeled in Unigraphics and a parasolid file of the 3-D model was created. The parasolid was imported into CFX5.4. This step in preprocessing saves considerable time in mesh generation. In CFX5.4 an unstructured 3-D mesh containing 1.3 million tetrahedral volumes was created using the parasolid as the baseline geometry of the room.

The room studied contains a "U-shaped" glove box. A glove box is a large enclosure used to perform laboratory operations safely in nuclear facilities. Typically glove boxes are operated at a negative pressure differential relative to atmospheric pressure to preclude leakage. The glove box and the other equipment are modeled as blocks. Glove box surfaces were treated as solid walls. A substantial amount of fine detail (pipes, conduit, furniture, etc.) was ignored in the model and the effects of this simplification were not evaluated.

Figure 1. Isometric view of the large SRS workroom.

Room size: $12.5 \mathrm{~m}$ by $11.8 \mathrm{~m}$ by $3.05 \mathrm{~m}$. Tetrahedrons: $1.3 \mathrm{M}$
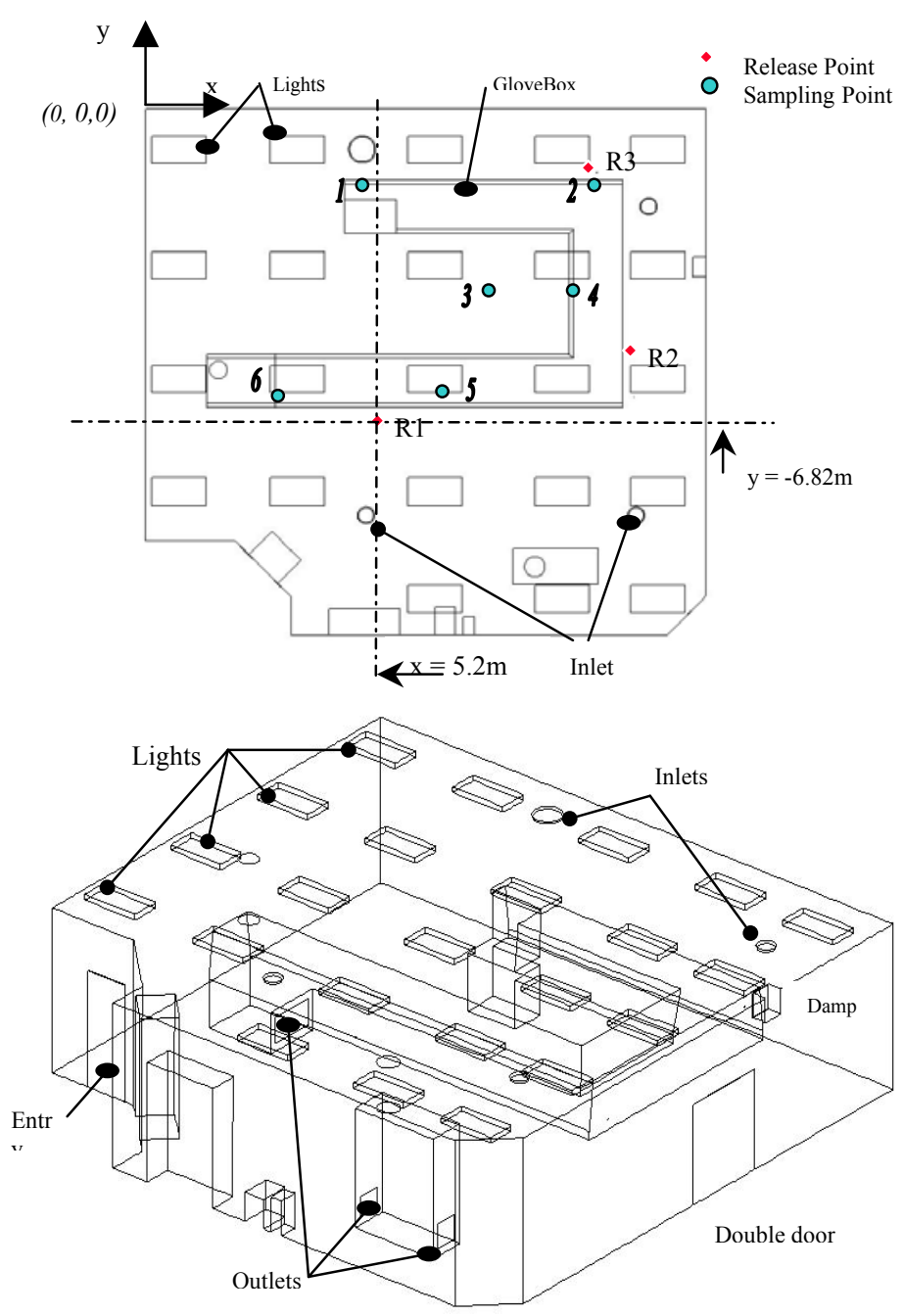

Figure 2. Plan view of the room.

Figure 2 shows a plan view of the room in which R1, R2, and R3, denote the "R-locations" of three aerosol releases performed during the experiments. The coordinates of these three points are listed in Table 1.

There are four ventilation inlets in the ceiling and three outlets near floor level. The inlets are circular diffusers. Three of them are 14-in. in diameter and one is 23-in. in diameter. One of the outlets is on the end at the bottom of the central glove box and the other two are under a cabinet containing glove box gas filtration apparatus. Flow at the inlets was measured with a volumetric hood and the direction of the air flowing into the room through the diffusers was measured with a thermal anemometer. Per the latter 
measurement, inlet air was modeled as a circumferential inflow at an angle of 25 degrees relative to the ceiling.

Table1. Locations of release and sampling points.

\begin{tabular}{|c|c|c|c|}
\hline & $\mathbf{X}(\mathbf{m})$ & $\mathbf{Y}(\mathbf{m})$ & $\mathbf{Z}(\mathbf{m})$ \\
\hline R1 & 5.2 & -6.8 & 1.27 \\
\hline R2 & 10.8 & -5.9 & 1.27 \\
\hline 1 & 10.0 & -9.6 & 1.27 \\
\hline 2 & 6.4 & -1.4 & 2.03 \\
\hline 3 & 10.6 & -2.1 & 2.03 \\
\hline 4 & 6.1 & -3.7 & 1.29 \\
\hline 5 & 9.5 & -4.2 & 2.03 \\
\hline 6 & 6.9 & -6.1 & 2.03 \\
\hline Breathing zone 1 & 3.8 & -6.1 & 2.03 \\
\hline Breathing zone 2 & 5.2 & -6.8 & 1.47 \\
\hline Breathing zone 3 & 11.0 & -5.9 & 1.47 \\
\hline
\end{tabular}

Inward airflow velocities leaking around the damper and doors was measured and applied as additional boundary conditions. During the experiments there were no heat sources or people in the room by design, so such effects were not considered in the model.

The air in the room was treated as incompressible and isothermal. The three-dimensional, steady state, flow field was computed using the k- $\varepsilon$ two-equation turbulence model.

\section{VELOCITY FIELD AND AEROSOL DISPERSION}

Velocity vectors (scaled in $\mathrm{m} / \mathrm{s}$ ) in two perpendicular vertical planes, obtained from the steady state CFD solution, are show in Fig. 3 and Fig. 4. Figure 2 shows the location and orientation of these planes. Figure 5 shows velocity vectors in a horizontal plane, and that re-circulation zones are formed in the lower left side of the room. In this figure, high velocities can be seen where air is flowing into the room through gaps around the door openings. Clearly, the flow in the room is complex and far from homogeneous. Data such as this is useful in evaluating and modifying the design of the laboratory and its ventilation system.

The steady-state CFD solution was used as an input in solving dispersion patterns for the aerosol releases. Transient calculations of the aerosol dispersion by advection, and molecular and turbulent diffusion were performed.

Three releases of an idealized aerosol (dilute, monodisperse, neutrally buoyant particles) at the R-locations were simulated with CFX5.4 using release durations of two minutes in agreement with the experimental approach. This method of tracking a scalar contaminant (or gas) provided a good approximation for aerosol particles that have an aerodynamic diameter of less than $1 \mu \mathrm{m}$. As a first approximation, this method is less data processor intensive than a multiphase or Lagrangian (individual) particle tracking simulation, which would have been required to simulate an aerosol with a size distribution or with multiple species with different densities.

The molecular diffusivity was specified to be $0.41 \mathrm{E}-4$ $\mathrm{m}^{2} / \mathrm{s}$, and the release rate was $1.0 \mathrm{E} 4 \mathrm{~kg} / \mathrm{m}^{3} \mathrm{~s}$. Dispersion of the gas was calculated for $300 \mathrm{~s}$. Calculated concentration of the gas was interpolated at nine locations corresponding to the experimental monitoring locations.

An example of concentration contours for a gas release at R1 (see Fig. 2) calculated at an elapsed time of $300 \mathrm{~s}$ is shown in Fig. 6. As can be seen, this dispersion was dominated by advection as hydrogen diffusion occurs at about $1 \mathrm{~cm} / \mathrm{s}$.

The solutions were obtained on a $600 \mathrm{MHz}$, single processor, Digital Equipment Corporation Alpha machines. The steady-state solution required about 8 hours using four parallel processors. The transient analysis required about 2$1 / 2$ days of continuous operation of a single processor in order to utilize CFX interpolation script to determine concentration.

\section{EXPERIMENTAL VALIDATION OF CFD MODEL}

The primary goal of the aerosol tracer measurements was to provide data on transport rates and dilution factors to validate CFD computations. As a secondary goal, the tracer releases and the subsequent analyses were used to provide additional information to SRS facility personnel about aerosol transport through the breathing zone, and about air monitor sampling locations. Techniques and results similar to those presented here are described in Whicker et al. (1997) and Whicker and Moxley (2001).

For this study, three release locations (see Table 1 and Fig. 2) were determined after discussions with SRS staff that operate the facility. The selected release locations were based on the most probable release scenarios. For instance, release locations R1, R2 and R3 were selected in front of glove box operations that are most likely to be the cause of a tritium release. Because of the nature of certain mechanical operations, the most probable release situation would be a breach of a glove. Therefore, the experimental aerosol releases at these R-locations were at the height of the gloves and at about $30-\mathrm{cm}$ in front of the glove box face. All releases were done remotely and no workers were in the room during the measurements.

To simulate a radioactive gas release, a non-toxic oil (Dioctyl Sebacate) aerosol was released during a $120 \mathrm{~s}$ "pufftype" event at the three R-locations described above. Two run repetitions were performed at each of the three R-locations to measure the variability of the aerosol dispersion. The particle generator ${ }^{1}$ has an output of up to $10^{8}$ per $\mathrm{cm}^{3}$ at a flow rate of between 1 and 4 liters per minute. The particle sizes generated were polydisperse with a geometric mean of about $0.3 \mu \mathrm{m}$ and a geometric standard deviation of less than two. These are very small particles that predominantly follow room airflow because of very low settling velocities and inertia (Hinds 1982). Thus, these small particles are good tracers for tritium (or other) gas, as well as certain ideal aerosols, in mechanically ventilated rooms where relatively high airflow rates exist that will dominate contaminant/tracer movement.

${ }^{1}$ Model 3079, TSI Incorporated, 500 Cardigan Rd., P.O. Box 64394, St. Paul, MN 55164-0394. 
After release into the room, aerosol dispersion through the room was measured using a network of seven laser particle counters (LPCs) ${ }^{2}$ that were connected to a multiplexer ${ }^{3}$. The seven LPCs were positioned at selected locations in the room (see sampling points in Fig. 2 and Table 2) and provided concentration measurements every $10 \mathrm{~s}$. In this manner, aerosol migration was measured in time and space. For the simulated releases, it was assumed that the cause was the result of a worker's action and not a random event. Therefore, one of the LPCs (Number 7, referred to as the breathing zone sampler) was positioned approximately $30 \mathrm{~cm}$ behind and above the aerosol generator for each of the three releases. This breathing zone sampler was intended to measure the concentration in the breathing zone (BZ) of the worker whose activity caused the release. Despite some inaccuracies introduced from this imperfect simulation of a collocated worker's exposure, this arrangement allowed for a useful comparison between $\mathrm{BZ}$ concentrations at the release location and concentrations elsewhere in the room. Finally, one LPC (Number 5) was placed within about 1-m to 2-m from an existing CAM intake tube for evaluation and comparison with other placement strategies.

\section{RESULTS}

Results from computational models are approximations. If practical, it is always desirable to check CFD results with an experiment. Here, CFD-predicted "lag time," a metric used to measure aerosol dispersion characteristics, was compared with experimental lag time data obtained at the same room locations and for the same conditions.

Lag time, shown in Fig. 7, is defined as the time interval between the start of the release until the concentration at a sampling location increased significantly to indicate the arrival of the tracer aerosol cloud. CAMs positioned such that the lag times are short are desirable for fast alarming.

Lag times determined with the CFX5.4 model were compared to those measured. The model lag time for each LPC location was determined by visually locating the time when there was an upward deflection such that concentration increased within an order-of-magnitude of the concentration range displayed. The correlation between numerically and experimentally derived lag times was determined using least squares linear regression.

Table 2 presents experimental and model lag time data as a function of release location and LPC number. Figure 8 shows the correlation between the experimental lag times and the model lag times. The linear correlation for all three release location combined was significant $(\mathrm{p}=0.02)$ with a correlation coefficient equal to 0.28 . Broken down by release location, the correlation coefficients were 0.62 for release location $1,0.003$ for release location 2, and 0.45 for release

\footnotetext{
2 Model 3755 and Model 7550, Particle Measuring Systems, 5475 Airport Boulevard, Boulder, CO 80301.

${ }^{3}$ Model 3701, TSI Incorporated, 500 Cardigan Road, P.O. Box 64394, St. Paul, MN 55164-0394.
}

location 3. This analysis shows that the CFD model more accurately predicted aerosol dispersion for releases R1 and R3 than for R2. Velocity vectors at a height of $1.47 \mathrm{~m}$ (see Fig. 5) show the complexity of airflow patterns predicted for the room, particularly near release location 2 where there is a strong inflow of air through the door along the nearest wall. This inflow probably had a strong impact on the actual aerosol dispersion, and although numerous measurements using a hotwire anemometer were made along this wall and door, it is possible that the inflow through this opening was so complex that it could not be characterized to a sufficient degree. Further, given the strong and highly turbulent flows at this location, it is possible that the CFD volume sizes used in the model were too large, and that smaller volumes are required for better accuracy.

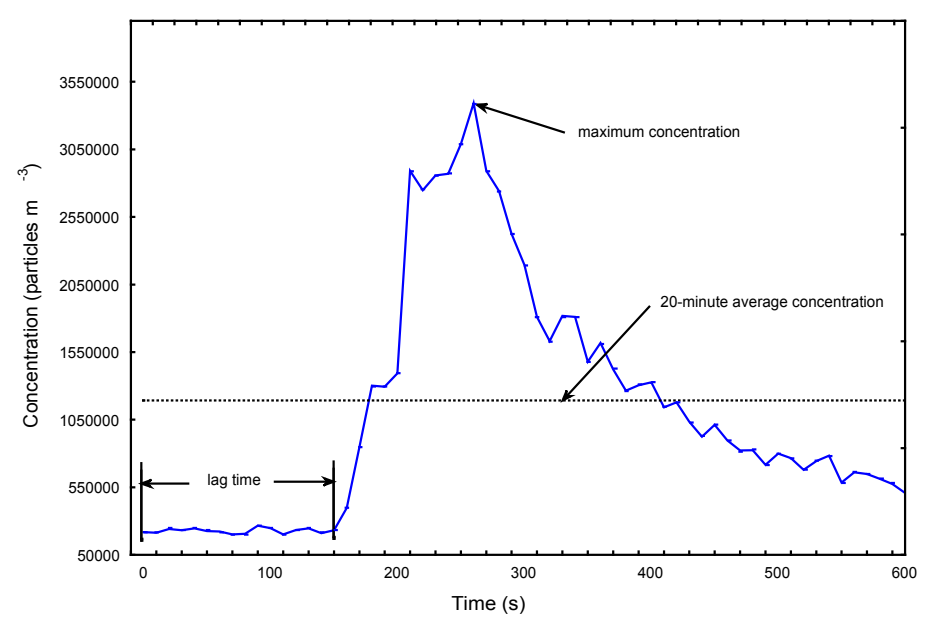

Figure 7. Time profile of concentration measured at a location with metrics of lag time, maximum concentration, and 20 minute average concentration.

The data in Fig. 8 suggests that the CFD model calculations yield aerosol dispersion lag time results that are in general agreement with experimental measurements. Similar validation work by Whicker et al. (2000) in the test room at the Los Alamos Group ESH-4-operated UHTREX test facility has shown general agreement between simulations and empirical measurements, as has the work presented in Konecni et al. (2000). These findings establish that once adequately parameterized, CFD modeling is capable of sufficient accuracy in representing patterns of room airflow and contaminant transport as to be a useful tool for optimizing the number and placement of detectors during design phases. In addition, it is anticipated that the CFD process will provide a better understanding of any spatial flexibility that operations personnel might have in placing the CAMs in an optimal configuration. 


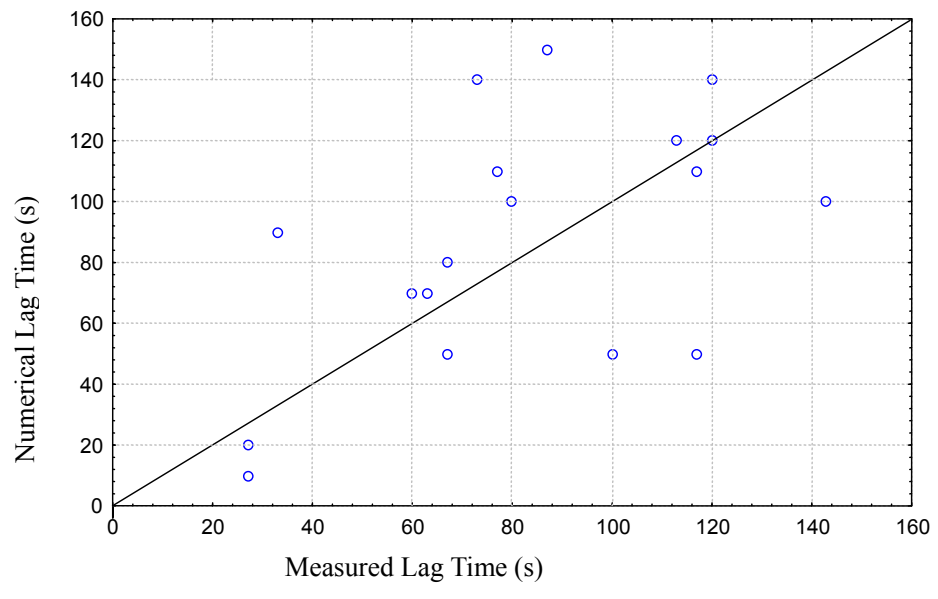

Figure 8. Predicted versus measured lag times for three aerosol releases in the SRS workroom.

Table 2. Lag time averages for experimental measurements and computer model.

\begin{tabular}{|l|l|l|l|}
\hline LPC Number & $\begin{array}{l}\text { Release } \\
\text { Location }\end{array}$ & $\begin{array}{l}\text { Lag time } \\
\text { Experiment(s) }\end{array}$ & $\begin{array}{c}\text { Lag time } \\
\text { Model (s) }\end{array}$ \\
\hline 1 & R1 & 120 & 120 \\
\hline 2 & R1 & 120 & 140 \\
\hline 3 & R1 & 80 & 100 \\
\hline 4 & R1 & 117 & 110 \\
\hline 5 & R1 & 63 & 70 \\
\hline 6 & R1 & 33 & 90 \\
\hline 1 & R2 & 143 & 100 \\
\hline 2 & R2 & 113 & 120 \\
\hline 3 & R2 & 77 & 110 \\
\hline 4 & R2 & 117 & 50 \\
\hline 5 & R2 & 67 & 50 \\
\hline 6 & R2 & 73 & 140 \\
\hline 1 & R3 & 100 & 50 \\
\hline 2 & R3 & 27 & 10 \\
\hline 3 & R3 & 60 & 70 \\
\hline 4 & R3 & 27 & 20 \\
\hline 5 & R3 & 67 & 80 \\
\hline 6 & R3 & 87 & 150 \\
\hline
\end{tabular}

\section{CONCLUDING REMARKS}

In this study, analytical (CFD) and experimental tools have been combined to form the basis of a new technology useful in the design and operation of nuclear facilities. Applications include ventilation system design, detector placement, accident analysis, and the mitigation of terrorist actions.

CFD velocity field results for a particular Savannah River Site nuclear facility are presented, which show complex airflow patterns that can complicate decisions about the placement of detectors. Computed and measured aerosol lag time data are compared and show general agreement.

The dispersion of aerosol or gas in a large room is advection dominated, as opposed to diffusion dominated. This was also observed in Konecni, et al., 2000. Molecular diffusion of hydrogen is relatively slow at about $1 \mathrm{~cm} / \mathrm{s}$ compared with advection velocities of about $25 \mathrm{~cm} / \mathrm{s}$ or so observed in this study and in Konecni, et al., 2000.

It is believed that with development, the techniques presented here can contribute toward safer facilities through (1) improvements in ventilation design which creates more protective airflow patterns, (2) optimization of the number and placement of aerosol or gas detectors in nuclear facilities, and (3) determination of optimal egress routes.

\section{ACKNOWLEDGMENTS}

The authors gratefully acknowledge the interest and support of Kurt Eberl, Jim Dollar, Don Greene, Bob Minnick, and Rick Orlowski, all at SRS, and technical support from AEA Technology Engineering Software, Inc.

\section{REFERENCES}

Alvarez, J.L., Bennett, W.S., and Davidson, T.L., 1994, "Design of an airborne plutonium survey program for personnel protection," Health Phys., 66:634-642, 1994.

Hinds, W.C., 1982, Aerosol technology: properties, behavior, and measurement of airborne particles, New York, John Wiley and Sons.

Konecni, S., Parietti, L., Whicker, J. J., and Martin, R. A., 2000, "Monitoring dispersion of aerosols in work rooms using computational fluid dynamics," Proceedings of the 2000 ASME Fluids Engineering Division Summer Meeting, June 11-15, Boston, MA.

McFarland, A.R., Rodgers, J.C., and Koskelo, M.J., 1997, "Sampling alpha-emitting transuranics aerosols in the nuclear workplace," Los Alamos National Laboratory Report LAUR97-3646.

Patankar, S.V., 1980, Numerical heat transfer and fluid flow, McGraw-Hill: New York, New York.

Van Dormaal, J.P. and Raithby, G.D., 1984, "Enhancements of the SIMPLE method for predicting incompressible fluid flows," Num. Heat Trans., Vol. 7, pp. 147-163.

Whicker, J.J., and Moxley, J., 2001, "Quantitative air migration study at the Savannah River Site CLAB," Los Alamos National Laboratory Report LA-UR-01-4933.

Whicker, J.J., Konecni, S., Parietti, L., Buhl, T., Hoover, M., Hoover, P., Martin, R.A., McAtee, J.L., Morgan, R., Rodgers, J.C., Voss, J.T., and Wannigman D., 2000, "Placement of continuous air monitors in PF-4 plutonium laboratories: consensus findings and recommendations," Los Alamos National Laboratory Report LA-UR-00-2311.

Whicker, J.J., Rodgers, J.C., Fairchild, C.I., Scripsick, R.C., and Lopez, R.C., 1997, "Evaluation of continuous air monitor placement in a plutonium facility," Health Phys. 73:734-743.

Whicker, J.J., Yang, Y, Rodgers, J.C., and Spore, J., 1996, "Experimental characterization and computational modeling of indoor aerosol dispersion and their applications in optimizing of continuous air monitor placement," Proceedings 
of the 1996 ASME Fluids Engineering Division Summer

Meeting, July 7-11, San Diego, CA.

\section{FIGURES 3, 4, 5, and 6}
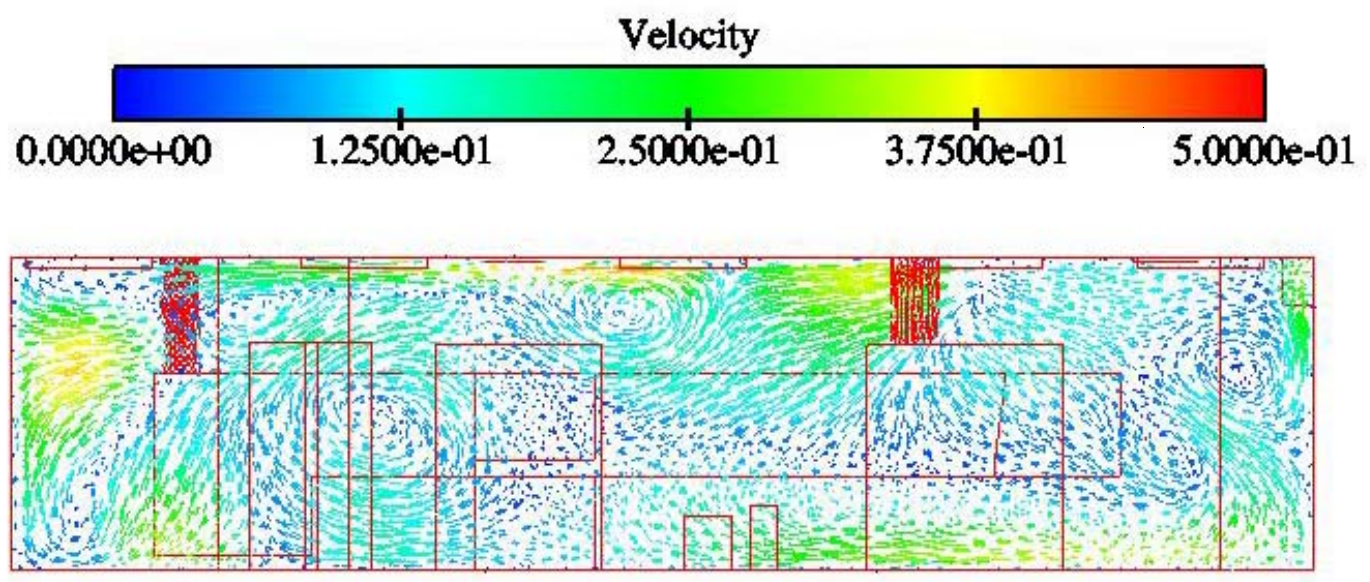

Release 1

\section{velocity vectors at $y=-6.82$}

Figure 3. Velocity vectors in a vertical x-plane containing release point 1 .

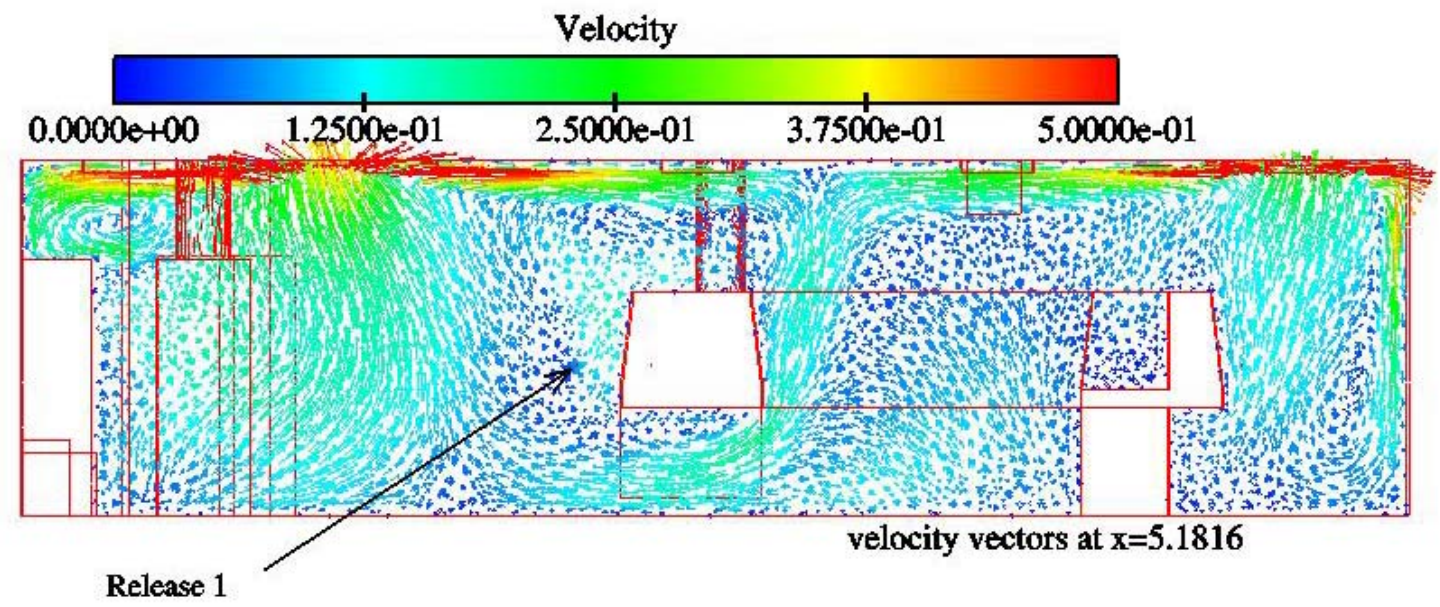

Figure 4. Velocity vectors in a vertical y-plane containing release point 1. 


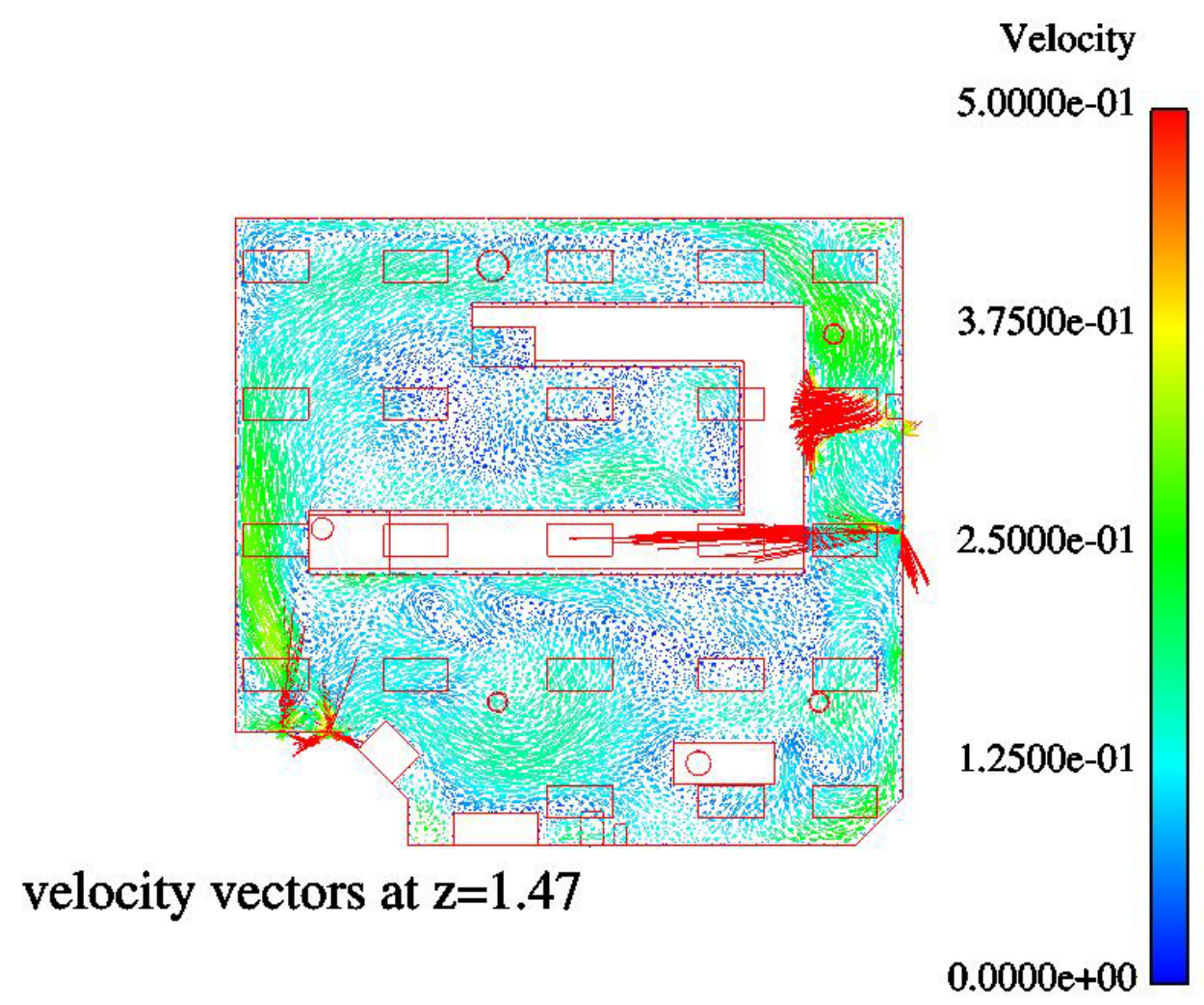

Figure 5. Velocity vectors in the horizontal plane $\mathrm{z}=1.47 \mathrm{~m}$ from the floor.

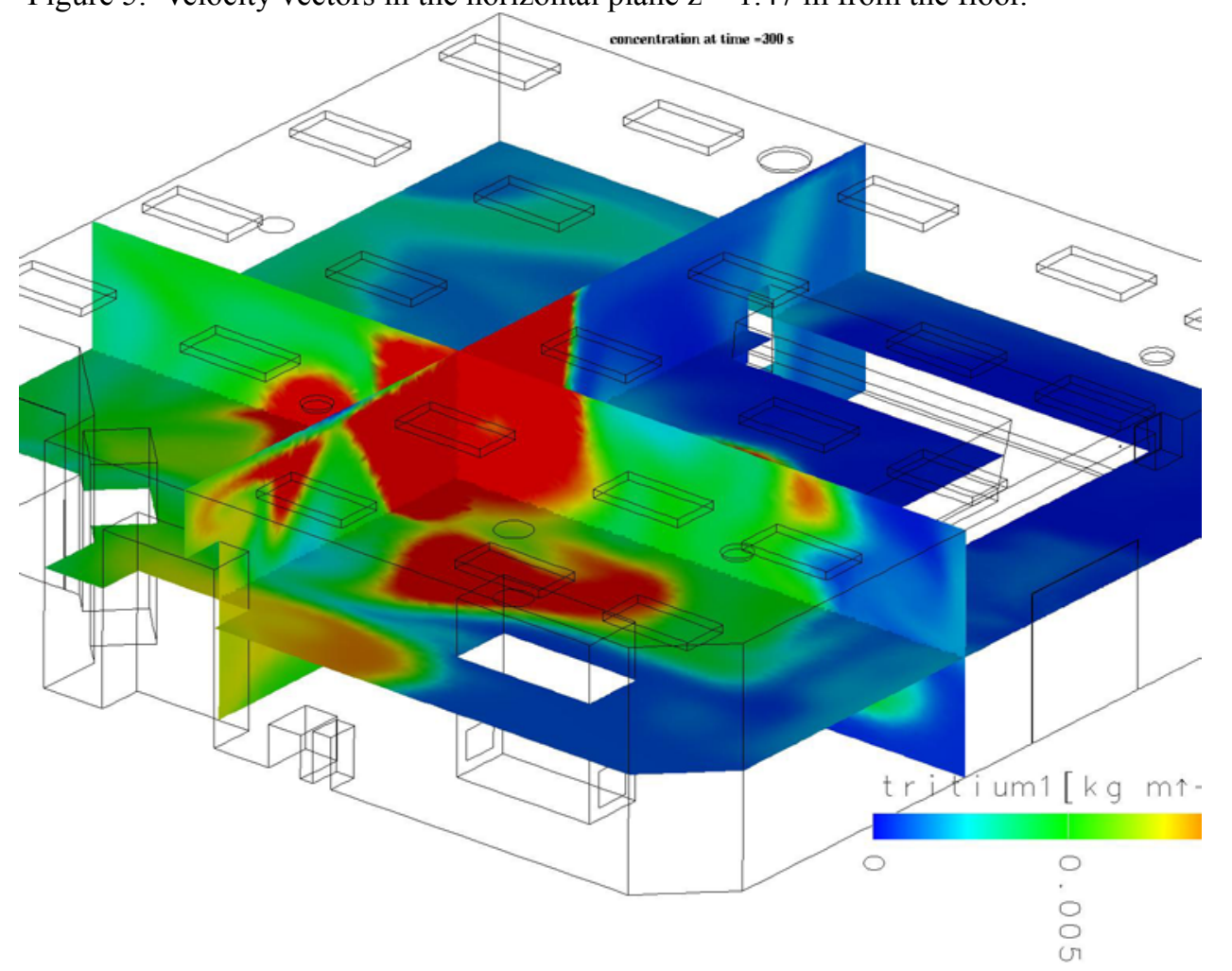

Figure 6. Scalar concentrations $(\mathrm{kg} / \mathrm{m} 3)$ in three intersecting planes that contain release point 1 at $\mathrm{t}=300 \mathrm{~s}$. 